\title{
Plan spawania boku kabiny ciągnika rolniczego
}

\section{Plan of welding the side of the cab of the farm tractor}

\section{Streszczenie}

Przedstawiono plan spawania boku kabiny ciągnika rolniczego. Omówiono kolejne etapy tego planu obejmujące wykaz elementów do spawania, cykl spawania, kolejność montażu w przyrządzie spawalniczym, spoiny o podwyższonych wymaganiach, kolejność spawania oraz kontrolę w toku produkcji. Plan spawania oparto na poglądowych trójwymiarowych rysunkach spawanego elementu.

Słowa kluczowe: spawanie, plan spawania, cykl spawania, kontrola jakości

\begin{abstract}
A plan of welding the side of the farm tractor's cab is presented in the above article. Following stages of this plan, including a list of components for welding, welding cycle, an order of assembly in the welding device, welds with high requirements, welding sequence and the control during production are discussed. The plan of welding is based ons illustrative three-dimensional drawings of the welded element.
\end{abstract}

Keywords: welding, welding plan, welding cycle, quality control

\section{Wstęp}

W niniejszym opracowaniu przedstawiono plan spawania boku kabiny ciągnika rolniczego. Celem planu spawania jest zapewnienie wysokiej jakości zarówno złączy spawanych jak i kompletnego wyrobu spawanego, zminimalizowanie błędów oraz ułatwienie prac spawalniczych poprzez dokładne określenie czynności, co niesie za sobą usprawnienie prac związanych z opisanym detalem [1 $\div 18]$.

Kompletny detal spawany jest z części i podzespołów (przygotowanych w poprzednich operacjach) wykonanych ze stali S355MC.

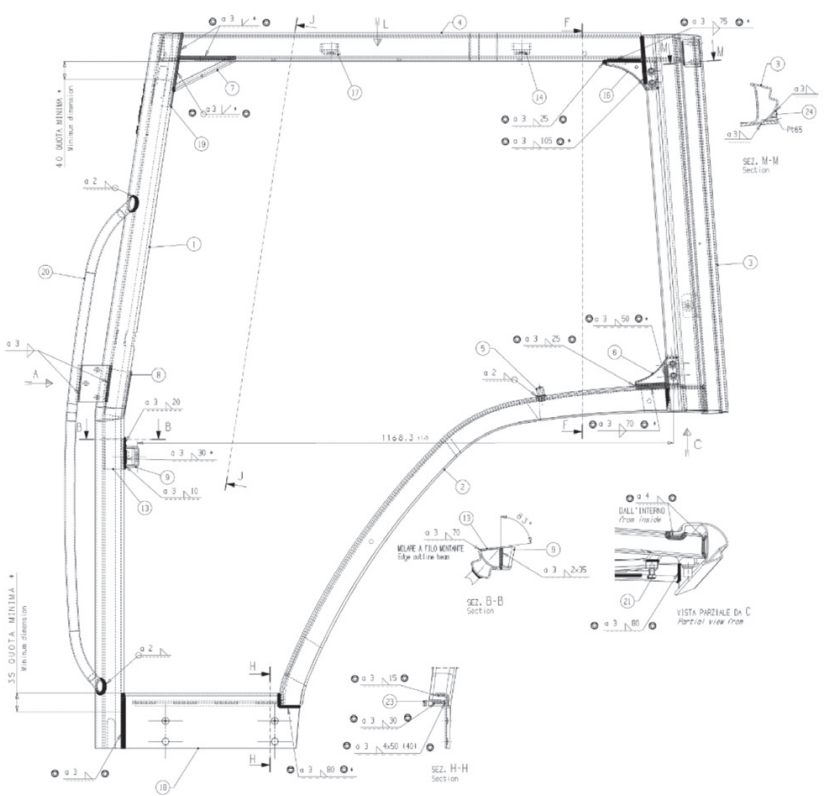

Rys. 1. Rysunek złożeniowy boku kabiny ciągnika rolniczego Fig. 1. An assembly drawing of the side of the cab of the farm tractor
Na rysunku 1 przedstawiono rysunek złożeniowy rozpatrywanego boku kabiny.

\section{Wykaz elementów do spawania}

W skład gotowego wyrobu wchodzi 9 części (tabl. I, rys. 2). Wszystkie wymienione części muszą być zgromadzone i przygotowane przed przystąpieniem do kolejnych etapów pracy.

Tablica I. Zestawienie tabelaryczne części i podzespołów do spawania Table I. The summary table of parts and components used for welding

\begin{tabular}{|c|c|c|c|c|}
\hline $\begin{array}{c}\text { Nr } \\
\text { zespołu: }\end{array}$ & L.p. & $\begin{array}{c}\text { Nr } \\
\text { części: }\end{array}$ & $\begin{array}{c}\text { Nazwa } \\
\text { części: }\end{array}$ & $\begin{array}{c}\text { Liczba } \\
\text { szt.: }\end{array}$ \\
\hline \multirow{4}{*}{ 0.ABC.12.315 } & 1 & $0 . A B C .12 .320$ & Belka przednia & 1 \\
\cline { 2 - 5 } & 2 & $0 . A B C .12 .321$ & Belka nadkola & 1 \\
\cline { 2 - 5 } & 3 & $0 . A B C .12 .322$ & Belka sufitowa & 1 \\
\cline { 2 - 5 } & 4 & $0 . A B C .12 .323$ & Belka tylna & 1 \\
\cline { 2 - 5 } & 5 & $0 . A B C .12 .324$ & Próg & 1 \\
\cline { 2 - 5 } & 6 & $0 . A B C .12 .325$ & $\begin{array}{c}\text { Uchwyt } \\
\text { ze wspornikiem } \\
\text { lusterka }\end{array}$ & 1 \\
\cline { 2 - 5 } & 7 & $0 . A B C .12 .326$ & Zamek & 1 \\
\cline { 2 - 5 } & 8 & $0 . A B C .12 .327$ & $\begin{array}{c}\text { Wzmocnienie } \\
\text { narożne 1 }\end{array}$ & 1 \\
\cline { 2 - 5 } & 9 & $0 . A B C .12 .328$ & $\begin{array}{c}\text { Wzmocnienie } \\
\text { narożne 2 }\end{array}$ & 2 \\
\hline
\end{tabular}

Dr hab. inż. Jacek Słania, prof. PCz; mgr inż. Sławomir Próchniak - Politechnika Częstochowska.

Autor korespondencyjny/Corresponding author. jacek.słania@is.gliwice.pl 


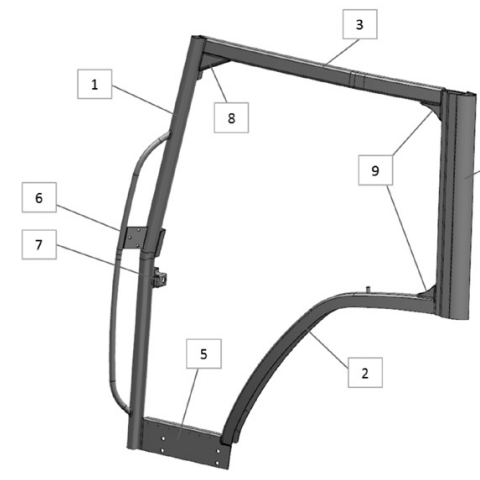

Cykl spawania

Cykl spawania obejmuje:

- Usunięcie oleju, rdzy i innych zanieczyszczeń z elementów przed spawaniem.

- Kontrolę liczby elementów do zespawania wg wykazu planu operacyjnego.

- Stosowanie zgodnie z WPS - parametrów spawania i wskazań do spawania.

- Zachowanie wymiarów spoin zgodne z rysunkiem konstrukcyjnym.

- Czyszczenie odprysków po spawaniu.

- Kontrolę wyrób wg karty kontroli.

\section{Kolejność montażu części/podzespołów w przyrządzie spawalniczym}

Kolejność montażu części w przyrządzie spawalniczym (Rys. 3).

Kolejność ta jest istotna ze względu na zachowanie określonego bazowania elementów oraz wyeliminowanie błędów montażowych.

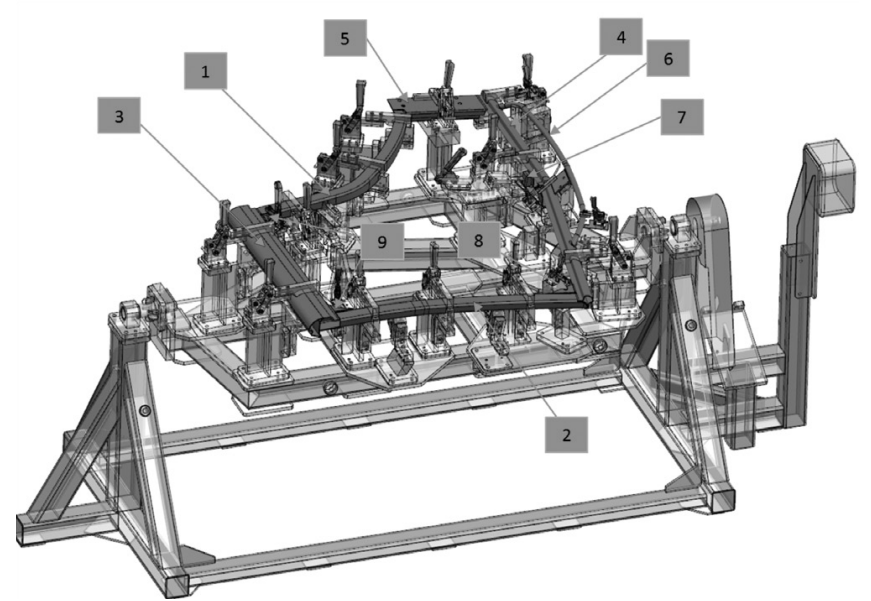

Rys. 3. Kolejność montażu części/podzespołów boku kabiny w przyrządzie spawalniczym

Fig. 3. A sequence of assembling parts/components of the side of the cab in the welding device

\section{Mapa spoin o podwyższonych wymaganiach}

$\mathrm{Na}$ rysunku 4 oznaczono spoiny, dla których zostały określone podwyższone wymagania. Są to spoiny mające istotny wpływ na wytrzymałość kompletnej kabiny podczas testów zderzeniowych. Ponadto określony został dla nich poziom C jakości niezgodności spawalniczych wg PN-EN ISO 5817. Spoiny te podlegają dodatkowym badaniom NDT przez dział kontroli jakości (100\% spoin oznaczonych jako spoiny o podwyższonych wymaganiach przechodzi badania wizualne i badania penetracyjne).

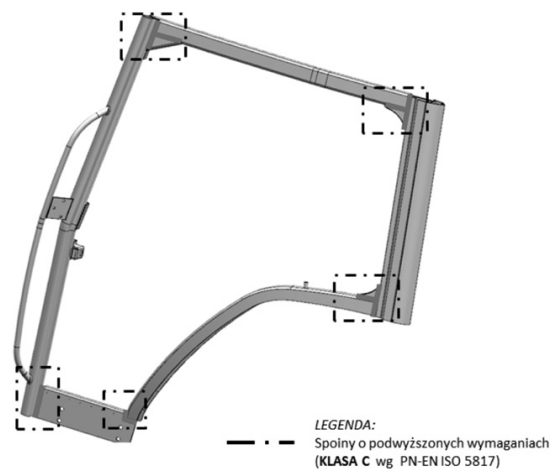

Rys. 4. Spoiny o podwyższonych wymaganiach

Fig. 4. Welds with increased requirements

\section{Kolejność spawania}

Kolejność układania spoin (Rys. 5) oraz rodzaje spoin i przypisane do nich numery Instrukcji Technologicznych Spawania (WPS). Zachowanie określonej kolejności spawania ma istotny wpływ na dokładność wymiarową detalu - wyeliminowanie lub zminimalizowanie odkształceń spawalniczych, ponadto kolejność ta uwzględnia ustawienia przyrządu spawalniczego zapewniające wykonywanie spawania w pozycjach "dogodnych".

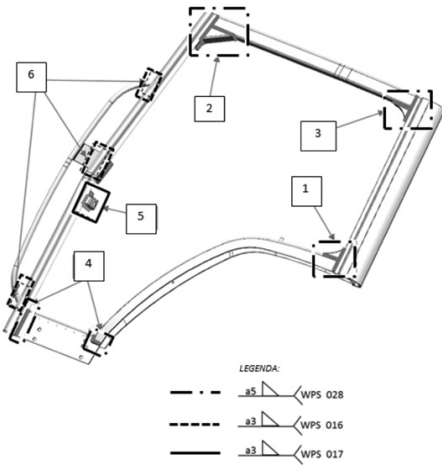

\section{Kontrola w toku produkcji}

Podano tu wytyczne dotyczące kontroli podczas spawania i gotowego oraz określono nazwy i numery dokumentów związanych.

Kontrolować w trakcie wykonywania serii produkcyjnej i potwierdzić na karcie kontroli:

A. Spoiny o podwyższonych wymaganiach wg instrukcji kontroli $\mathrm{nr} \mathrm{ABC}$ 1,

B. Ocena w obszarze spawania:

- Spoiny o podwyższonych wymaganiach wg instrukcji kontroli nr ABC 2,

- Brak spoiny - niedopuszczalny,

- Wadliwy ścieg- niedopuszczalny,

- Niekompletne wypełnienie- niedopuszczalne,

- Pory - niedopuszczalne,

- Wadliwe połączenie - niedopuszczalne,

- Odpryski spawalnicze na powierzchniach przyszybowych - niedopuszczalne.

B. Inne:

- Zgodność parametrów z WPS,

- Kompletność elementów po spawaniu.

\section{Załączniki (Karta kontroli)}

Karta kontroli stanowi integralną część planu spawania i całego procesu wytwarzania wyrobu. Określone są w niej wszystkie elementy kontrolowane i zapisy dotyczące jakości. 


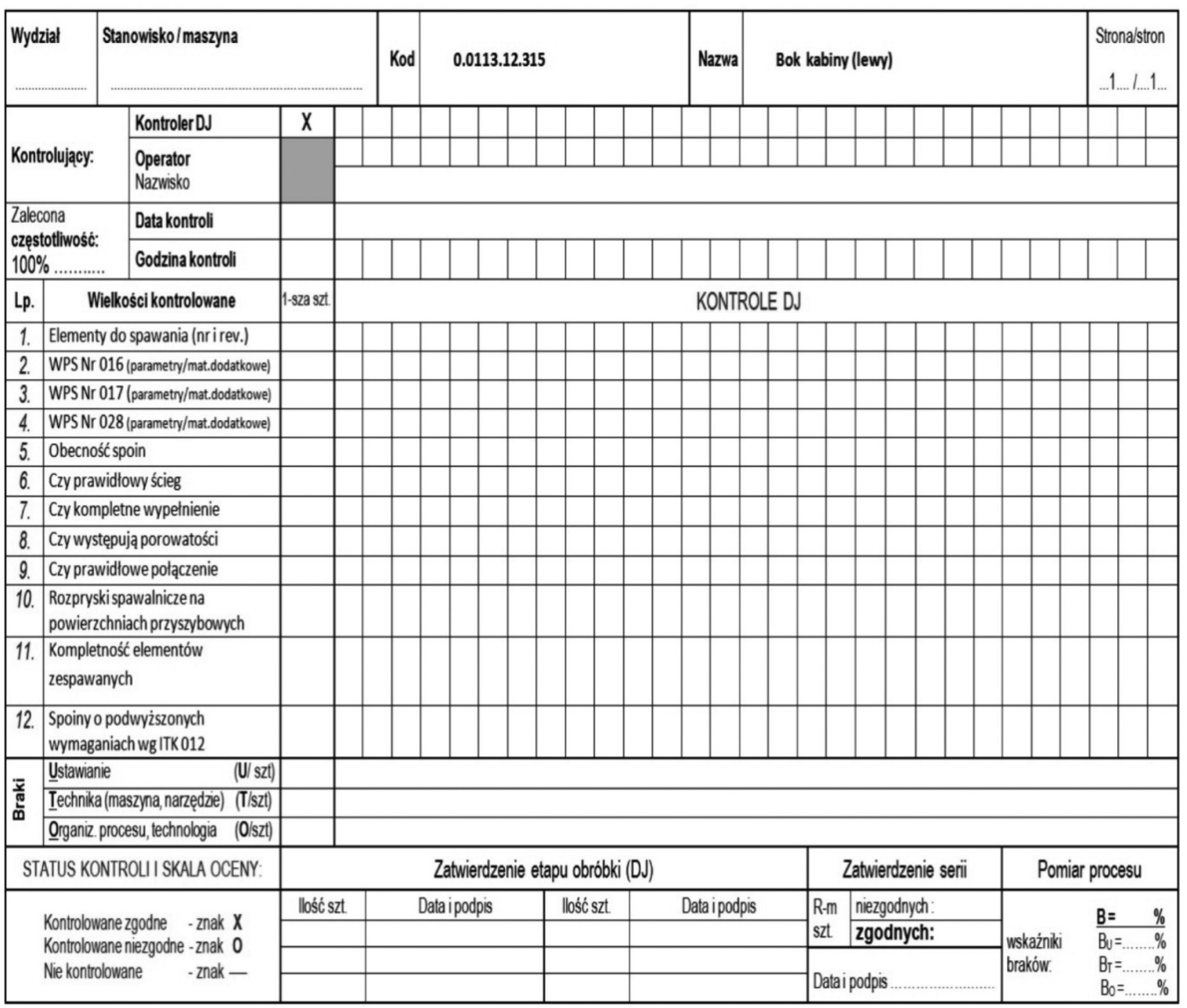

\section{Podsumowanie}

Przedstawiony plan spawania stanowi przykład opracowywania uproszczonych planów w przypadku spawania dużych serii wyrobów np. w przemyśle samochodowym lub maszyn rolniczych. Obejmuje podstawowe elementy technologiczne dotyczące montażu w oprzyrządowaniu spawalniczym, kolejności wykonywania spoin, wymagań jakościowych dotyczących spoin oraz zapisów wyników kontroli.

\section{Literatura}

[1] Słania J.: Skóra J.: Plan spawania wymiennika ciepła chłodzonego powietrzem Przegląd spawalnictwa nr 2/2011,str. 19-26.

[2] Słania J.: Plany spawania. Teoria i praktyka. Agenda Wydawnicza SIMP, Warszawa 2013.

[3] Słania J.: Plan technologiczny spawania płyty gąsienicowej. Przegląd Spawalnictwa, 2010, nr 3, str. 16-25.

[4] Słania J., Kaczor T.: Plan spawania zbiornika ciśnieniowego. Przegląd Spawalnictwa, 2010, nr 4, str. 9-18.

[5] Słania J., Kwiecień L., Jarosiński J.: Plan spawania kotłów płomienicowo - płomieniówkowych. Przegląd Spawalnictwa, 2010, nr 6, str. 32-40.

[6] Słania J., Skóra J.: Plan spawania wymiennika ciepła chłodzonego powietrzem. Przegląd Spawalnictwa 2011, nr 2, str. 16-22.

[7] Słania J.: Plan spawania carg płaszcza pieca obrotowego. Przegląd Spawalnictwa 2011, nr 2, str. 36-41.

[8] Słania J., Wodecki D.: Plan spawania belki poprzecznej dźwigu. Przegląd Spawalnictwa 2011, nr 2, str. 30-35.

[9] Słania J.: Istota planów spawania. Przegląd Spawalnictwa 2011, nr 2, str. 3-9.

[10] Słania J.: Plan spawania napraw bieżących kotłów parowych, wodnych i stałych zbiorników ciśnieniowych. Przegląd Spawalnictwa 2011, nr 2, str. 22-30.
[11] Słania J., Kwiecień L., Jarosiński J.: Kotły płomienicowo - płomieniówkowe - plan spawania oraz kontroli i badań. Dozór Techniczny 2011, nr 2, str. 35-41.

[12] Słania J., Chomiuk S., Dadak R.: Plan spawania dla konstrukcji uzupełniającej - trawresy. Przegląd Spawalnictwa 2012, nr 2, str. 3-6.

[13] Słania J., Marcinkiewicz H., Kiełbik M.: Plan spawania elementu obudowy kopalnianej - osłony odzawałowej. Przegląd Spawalnictwa 2012, nr 2, str. 6-16.

[14] Słania J., Fryc H.: Spawanie pojazdów szynowych - plany spawania. Przegląd Spawalnictwa 2012, nr 2, str. 16-20.

[15] Słania J.: Plan spawania stalowej kładki dla pieszych I. Przegląd Spawalnictwa 2012, nr 2, str. 20-24.

[16] Słania J.: Plan spawania stalowej kładki dla pieszych II. Przegląd Spawalnictwa 2012, nr 2, str. 24-26.

[17] Słania J., Urbańczyk P.: Technologia wytwarzania oraz plan kontroli jakości przegrzewacza pary kotła parowego wg PN-EN 12952-5. Przegląd Spawalnictwa 2012, nr 5, str. 29-41.

[18] Chromik D., Słania J.: Plan spawania ciśnieniowego zespołu rurowego. Przegląd Spawalnictwa 2012, nr 11, str. 29-32. 